\title{
Time space distribution of childhood leukaemia in the Netherlands
}

\author{
H A VAN STEENSEL-MOLL,${ }^{1}$ H A VALKENBURG,${ }^{2} \mathrm{~J}$ P VANDENBROUCKE, ${ }^{2}$ AND \\ G E VAN ZANEN'
}

From the Dutch Childhood Leukaemia Study Group, ${ }^{1}$ The Hague, and Institute of Epidemiology, ${ }^{2}$ Erasmus University Rotterdam, the Netherlands

SUMMARY In the western part of the Netherlands during 1973-80 leukaemia was diagnosed in 293 patients aged under 15 years. An overall incidence rate of 2.91 per 100000 person years was calculated. No seasonal influence on months of birth or months of diagnosis of these patients could be traced by the method of Edwards. Time space clustering was looked for by both methods of Mantel and Knox. No significant time space clustering of date and place of diagnosis of childhood leukaemia was found in all types of leukaemia, acute lymphocytic leukaemia (ALL), ALL in boys and girls, ALL in children under 6 years at diagnosis, and in acute non-lymphocytic leukaemia.

The results of studies of temporal and spatial distribution of childhood leukaemia are not consistent and are even contradictory. ${ }^{1}$ Clustering of cases might be caused by an environmental agent acting in a limited geographical area for a limited period. This could be most easily detected in childhood leukaemia because of the limited mobility of children compared with adults, which may facilitate the observation of clusters.

The existence of a complete seven year nation wide registry of childhood leukaemia offered us the opportunity to look for time space clustering in the densely populated western part of the country.

\section{Material and methods}

The morbidity registry of the Dutch Childhood Leukaemia Study Group (DCLSG) was established in 1972. It covers the whole country, which in 1976 had a childhood population ( $<15$ years) of nearly $3 \cdot 4 \mathrm{~m}$ (total population $13 \cdot 9 \mathrm{~m}$ ).

Nearly 160 paediatricians in the Netherlands collaborate in the DCLSG in an effort to optimise the treatment of children with leukaemia. They routinely send blood and bone marrow slides of each child with leukaemia or under suspicion of this disease to the DCLSG laboratory. These slides are reviewed according to previously determined criteria by two independent experts. Before 1975 the DCLSG laboratory used its own diagnostic criteria based on morphology and cytochemistry (Sudan black and periodic acid-Schiff (PAS)). Since 1975 the
French-American-British (FAB) classification has been used. ${ }^{2} 3$ The treatment of these children is centrally coordinated and clinical information is uniformly collected.

In 1980 the completeness of the morbidity registration was checked by sending a questionnaire to all 462 paediatricians in the Netherlands. They were asked to give the names, dates of birth, dates of diagnosis, and sex of all patients with leukaemia whom they had treated or consulted between 1973 and 1980. The overall response rate to the questionnaire was $92.6 \%$, and 17 cases, hitherto unknown, were reported. Bone marrow slides of 12 of these patients were still available, and the diagnosis of leukaemia could be confirmed at the DCLSG laboratory. We estimate that over $95 \%$ ascertainment of patients had been achieved in the period 1973-80.

The patients with leukaemia who were accepted for this study were all under 15 at the time of diagnosis (1 January 1973 until 1 January 1980). The diagnosis was confirmed by bone marrow slides at the DCLSG laboratory. The cluster analysis was limited to the western part of the Netherlands, comprising the provinces of North Holland, South Holland, and Utrecht, because the home address at diagnosis of each patient could be located on a geographical map with a scale of 1:50 000. Within this map the addresses in larger towns were identified with the use of large scale street maps. This part of the Netherlands covers about $7677 \mathrm{sq} \mathrm{km}$. In 1976 the childhood population (0-15 years) was $1.44 \mathrm{~m}$. It has 
the highest population density in the Netherlands and is nearly uniformly urbanised. This has the advantage that the same distance between patients does have an equal meaning.

For the cluster analysis, the date of the diagnostic bone marrow sample was chosen, and this represents the date of diagnosis. A seasonal trend in month of birth or month of diagnosis of leukaemic patients was examined by using the analysis of monthly frequencies of Edwards. ${ }^{4}$

The methods of Knox ${ }^{5}$ and Mantel ${ }^{6}$ were used to investigate time space interaction. Both analyses are based on examination of time and distance intervals between all possible pairs of cases. The hypothesis that pairs of patients who are close in time are also close in space is tested. Mantel's method uses a time versus space regression. For each possible pair of patients, say patient $i$ and patient $j$, a spatial measure of $\mathrm{Xij}$ and a temporal measure $\mathrm{Yij}$ is obtained. A clustering measure is given by test statistic:

$$
\mathrm{Z}=\mathbf{X i j} \cdot \mathbf{Y i j}
$$

Evidence of time space clustering is given if the observed $Z$ differs significantly from the permutational expectation of $Z$

$$
\chi=\frac{Z-E(Z)}{S E(Z)}
$$

In concept, the set of time and space locations for the patients are split apart and then put back together at random. Each possible way of putting them back together results in a new value for $\mathrm{Z}$. Mantel describes how to determine approximately the expected $\mathrm{Z}$ and the standard error of $\mathrm{Z}$ under normal assumptions, so that the departure of the observed $Z$ from its expected value can be tested for significance.

In this study the reciprocal value of time and distance intervals between pairs of patients was used in Mantel's cluster analysis. In this way the short distances will be spread out while collapsing the range of great distances. Temporal and space distances equal to zero were replaced by the value 3 .

In the method of Knox ${ }^{5}$ each pair is classified as being close or far apart in time and close or far apart in space to form a $2 \times 2$ contingency table. The expected number of pairs may be calculated from the marginal totals. The observed number of close pairs is tested as a Poisson deviate from the expected number. In this model critical time and distance intervals are arbitrarily chosen.

In our analysis $2 \mathrm{~km}$ distance intervals $(2,4,6,8$, and 10$)$ and time intervals of two months $(2,4,6,8$, 10 , and 12) were used.

Analyses according to Edwards, ${ }^{4} \mathrm{Knox}^{5}$ and Mantel $^{6}$ were performed for the total group of patients and for different subgroups classified according to type of leukaemia, tumour load (initial leucocyte counts over $50000 / \mathrm{mm}^{3}$ ), age (younger than 6 years at diagnosis $\left.{ }^{6-9}\right)$, and sex.

\section{Results}

During 1973-80 in the western part of the Netherlands leukaemia was diagnosed in 293 patients aged under 15 years. This amounts to an incidence rate of 2.91 per 100000 person years (standard error $(S E)=0 \cdot 17)$. Acute lymphocytic leukaemia (ALL) was the most common type compared with acute non-lymphocytic leukaemia (ANLL) and chronic myeloid leukaemia (CML, including the juvenile and adult type)-that is, $79.5 \%, 16.7 \%$, and $2 \cdot 4 \%$, respectively. In $1.4 \%$ the type could not be classified.

The patients' months of diagnosis or months of birth were examined for evidence of a seasonal trend. The analyses were performed for all patients, patients with ALL, the subgroups of boys and girls with ALL, patients with ALL younger than 6 years ato diagnosis, patients with initial counts $\geqslant 50000$ leucocytes $/ \mathrm{mm}^{3}$, and patients with ANLL. No significant seasonal variation was found. Table 1 gives the results for ALL.

Table 2 gives the results of time space clustering using Mantel's method. No significant clustering of date and place of diagnosis was detected-neither for all leukaemic patients nor for the different subgroups of patients (all $p$ values for analysis $>0 \cdot 10$ ).

Table 3 shows the results of Knox's analysis of children with leukaemia at a critical space distance of $2 \mathrm{~km}$ and three critical time distances of two, four, and six months. The null expectation did not show a departure from the observed number of close pairs classified according to type, age, and sex ( $p$ values $>0 \cdot 10$ ). Only clustering of patients with ALL with initial count $\geqslant 50000$ leucocytes $/ \mathrm{mm}^{3}$ was found. This consists of a higher number of pairs with a distance separation of under $2 \mathrm{~km}$ and a time separation of under six months. Four pairs were found while the expected number was 1.4. This difference was statistically significant $(x=2 \cdot 20$, one-sided $\mathrm{p}<0.025){ }^{*}$

\section{Discussion}

Knox $^{5}$ did not find a seasonal influence on the months 
Table 1 Seasonal incidence of acute lymphocytic leukaemia

\begin{tabular}{|c|c|c|c|c|c|c|c|c|c|c|c|c|}
\hline & \multicolumn{12}{|c|}{ Months } \\
\hline & 1 & 2 & 3 & 4 & 5 & 6 & 7 & 8 & 9 & 10 & 11 & 12 \\
\hline $\begin{array}{l}\text { With regard to diagnosis } \\
\text { With regard to birth }\end{array}$ & $\begin{array}{l}17 \\
26\end{array}$ & $\begin{array}{l}23 \\
17\end{array}$ & $\begin{array}{l}22 \\
12\end{array}$ & $\begin{array}{l}16 \\
16\end{array}$ & $\begin{array}{l}19 \\
24\end{array}$ & $\begin{array}{l}18 \\
28\end{array}$ & $\begin{array}{r}20 \\
9\end{array}$ & $\begin{array}{l}20 \\
25\end{array}$ & $\begin{array}{l}15 \\
14\end{array}$ & $\begin{array}{l}17 \\
27\end{array}$ & $\begin{array}{l}29 \\
20\end{array}$ & $\begin{array}{l}17 \\
15\end{array}$ \\
\hline
\end{tabular}

Table 2 Time space cluster analysis by Mantel's method ${ }^{6}$

\begin{tabular}{|c|c|c|c|c|c|c|c|}
\hline & All types & $A L L$ & $A L L$ (boys) & $A L L$ (girls) & $A L L$ (<6 years) & $A L L\left(\geqslant 50000 / \mathrm{mm}^{2}\right)$ & $A N L L$ \\
\hline $\begin{array}{l}\text { No } \\
Z \\
E(Z) \\
\text { SE } \\
X\end{array}$ & $\begin{array}{r}293 \\
20.91 \\
21.90 \\
1.75 \\
-0.56\end{array}$ & $\begin{array}{r}233 \\
12.17 \\
13.64 \\
1.29 \\
-1.14\end{array}$ & $\begin{array}{r}133 \\
3.51 \\
3.94 \\
0.57 \\
-0.75\end{array}$ & $\begin{array}{r}100 \\
2.50 \\
2.93 \\
0.89 \\
-0.48\end{array}$ & $\begin{array}{l}159 \\
5 \cdot 37 \\
6 \cdot 17 \\
0 \cdot 72 \\
1 \cdot 11\end{array}$ & $\begin{array}{l}43 \\
0.71 \\
0.52 \\
0.39 \\
0.49\end{array}$ & $\begin{array}{l}49 \\
0.50 \\
0.55 \\
0.15 \\
0.33\end{array}$ \\
\hline
\end{tabular}

ALL = Acute lymphocytic leukaemia.

ANLL = Acute non-lymphocytic leukaemia.

Table 3 Time space cluster analysis by Knox's method

\begin{tabular}{|c|c|c|c|c|c|c|c|c|}
\hline \multirow{2}{*}{\multicolumn{2}{|c|}{$\begin{array}{l}\text { Time separations } \\
\text { between pairs of } \\
\text { cases in months }\end{array}$}} & \multicolumn{7}{|c|}{$\leqslant 2 \mathrm{~km}$ space separation between pairs of cases } \\
\hline & & \multirow{2}{*}{$\begin{array}{c}\text { All types } \\
12 \\
13.5\end{array}$} & \multirow{2}{*}{$\begin{array}{l}\frac{A L L}{6} \\
9.00\end{array}$} & \multirow{2}{*}{$\begin{array}{l}A L L \text { (boys) } \\
0 \\
2 \cdot 3\end{array}$} & \multirow{2}{*}{$\begin{array}{l}A L L \text { (girls) } \\
1 \\
2 \cdot 2\end{array}$} & \multirow{2}{*}{$\begin{array}{c}A L L(<6 \text { years }) \\
2\end{array}$} & \multicolumn{2}{|c|}{$A L L\left(\geqslant 50000 / \mathrm{mm}^{2}\right) A N L L$} \\
\hline$\leqslant 2$ & $\begin{array}{l}\text { Obs } \\
\text { Exp }\end{array}$ & & & & & & $\begin{array}{l}1 \\
0.4\end{array}$ & $\begin{array}{l}0 \\
0.2\end{array}$ \\
\hline & $x$ & -0.41 & -1.00 & -1.52 & -0.81 & -0.84 & 0.95 & -0.45 \\
\hline$\leqslant 4$ & Obs & 27 & 15 & 0 & 4 & 4 & 1 & 0 \\
\hline & $\operatorname{Exp}_{x}$ & $\begin{array}{c}26 \cdot 3 \\
0 \cdot 14\end{array}$ & $\begin{array}{c}17.4 \\
-0.58\end{array}$ & $\begin{array}{c}4 \cdot 2 \\
-2.05\end{array}$ & $\begin{array}{c}4 \cdot 3 \\
-0 \cdot 14\end{array}$ & $\begin{array}{c}6.8 \\
-1.07\end{array}$ & 0.9 & 0.5 \\
\hline \multirow[t]{3}{*}{$\leqslant 6$} & Obs & 40 & 26 & 3 & $\begin{array}{l}-0 \cdot 14 \\
5\end{array}$ & 6 & 4 & 0 \\
\hline & Exp & $39 \cdot 2$ & $25 \cdot 8$ & $6 \cdot 3$ & $6 \cdot 2$ & 9.9 & 1.4 & 0.7 \\
\hline & $x$ & $0 \cdot 13$ & 0.04 & $-1 \cdot 31$ & -0.48 & -1.24 & $2 \cdot 20^{*}$ & -0.84 \\
\hline
\end{tabular}

- Significant $\mathrm{p}<0.025$.

ALL = Acute lymphocytic leukaemia.

ANLL = Acute non-lymphocytic leukaemia.

of birth for children with leukaemia. This agrees with our result. Most previous investigations, ${ }^{7-10}$ except one study in England, ${ }^{5}$ did not establish any significant seasonal variation for the months of diagnosis. Neither in this study was any seasonal influence on the month of diagnosis found.

Knox $^{5}$ in Northumberland and Durham, Till et al ${ }^{7}$ in London, and Gunz and Spears ${ }^{8}$ in New Zealand detected weak evidence of clustering of date and place of diagnosis in patients with leukaemia aged under 6 years at diagnosis with Knox's statistical method. In London even clustering of date and place of birth was shown. Mantel's cluster analysis was also used on the data in New Zealand.9 The results confirm time and space clustering of childhood leukaemia. The authors, however, suggest that this finding is perhaps due to shifting population patterns and unequal population growth.

In Connecticut ${ }^{10}$ and Michigan ${ }^{11}$ cases of childhood leukaemia were analysed for time space interaction.
In these studies discrete units of space function as cells in which the distribution of the patients over time is tested for random distribution. The time and distance boundaries were arbitrarily chosen. The results show no significant clustering.

In San Francisco ${ }^{12}$ and Lewisham ${ }^{13}$ no time space interaction of childhood leukaemia was detected with Knox's method.

A reanalysis of the death certificates of leukaemic children in London with a generalised approach of Knox's analysis in which time and distance intervals and arbitrary periods of latency and suspectibility of leukaemia were taken into account established no evidence of time space clustering. ${ }^{14}$

The studies about time space clustering in childhood leukaemia have either produced negative findings or weak positive findings. In this study we found no evidence for time space clustering in the total group of patients nor in the subgroups classified according to type, age, and sex. 
The method of analysis can influence the results of time space clustering. In the western part of the Netherlands time space analysis of leukaemic patients do only show clustering with Knox's method for patients with ALL with high initial leucocyte counts $\left(\geqslant 50000 / \mathrm{mm}^{3}\right)$. Mantel's method, however, could not confirm this finding. Considering the exploratory nature of Knox's analysis, which uses varying critical distance intervals, the clustering could be a chance event.

In the Netherlands we found no seasonal variation in months of birth or months of diagnosis of children with leukaemia. Also no significant time space clustering of childhood leukaemia was traced. The restrictions of the statistical methods of cluster analysis have to be taken into account. Long latency periods of aetiological factors could mask clustering. Furthermore, the patients were classified according to cytomorphological criteria and one wonders if these subgroups with leukaemia are homogeneous with regard to the aetiology.

We thank all paediatricians in the Netherlands who have so willingly contributed information and material to the registry. We are grateful for the advice of A Hofman, P I M Schmitz, A van der Does-van den Berg, the board of the DCLSG, and the staff of the Institute of Epidemiology, Erasmus University Rotterdam. We also thank E R van Wering and E C Vissers-Praalder for their review of blood and bone marrow samples and $M$ de Ruiter-van Beelen and Y E J M Jongepier-Geerdes for the administrative work. We also thank $G A$ M Eilers, A van Laar, and L Muller for the computer programming and advice about the analysis.
This study was supported by a grant from the Ministry of Public Health and Environmental Hygiene.

\section{References}

${ }^{1}$ Caldwell GG, Heath CW. Case clustering in cancer. South Med J 1976; 69: 1598-1602.

${ }^{2}$ Van Wering ER, Vissers-Praalder EC. Morfologie en cytochemie van bloed-en beenmergpreparaten bij acute leukemie. Tijd kindergeneesk 1979; 47: 73-80.

${ }^{3}$ Bennet JM, Catovsky D, Daniel MT et al. Proposals for the classification of the acute leukaemias. Br J Haematol 1976; 33: 451-8.

${ }^{4}$ Edwards JH. The recognition and estimation of cyclic trends. Ann Hum Genet 1961; 25: 83-7.

${ }^{5} \mathrm{Knox}$ G. Epidemiology of childhood leukaemia in Northumberland and Durham. Br J Prev Soc Med 1964; 18: 17-24.

${ }^{6}$ Mantel $\mathrm{N}$. The detection of disease clustering and a generalised regression approach. Cancer Res 1967; 27: 209-20.

${ }^{7}$ Till MM, Hardisty RM, Pike MC, Doll R. Childhood leukaemia in Greater London: a search for evidence of clustering. Br Med J 1967; iii: 755-8.

${ }^{8} \mathrm{Gunz}$ FW, Spears GFS. Distribution of acute leukaemia in time and space. Studies in New Zealand. Br Med J 1968; iv: 604-8.

${ }^{\circ}$ Glass AG, Mantel N, Gunz FW, Spears GFS. Time space clustering of childhood leukaemia in New Zealand. $J$ Natl Cancer Inst 1971; 47: 329-36.

${ }^{10}$ Ederer F, Myers MH, Mantel N. A statistical problem in space and time: do leukemia cases come in clusters?

Biometrics 1964; 20: 626-38.
${ }^{11}$ Stark CR, Mantel N. Temporal-spatial distribution of $\overrightarrow{6}$ birth dates for Michigan children with leukemia. Cancer? Res 1967; 27: 1749-75.

${ }^{12}$ Klauber MR, Mustacchi P. Space time clustering of childhood leukemia in San Francisco. Cancer Res 1970; 30: 1969-73.

${ }^{13}$ Lock SP, Merrington M. Leukaemia in Lewisham (1957-63). Br Med J 1967; iii: 759-60.

${ }^{14}$ Smith PG, Pike MC, Till MM, Hardisty RM. Epidemiology of childhood leukaemia in Greater London: a search for evidence of transmission assuming a possible long latent period. Br J Cancer 1976; 33: 1-8. 